\title{
Overexpression of HER2/neu as a Prognostic Value in Iranian Women With Early Stage Breast Cancer; A Single Institute Study
}

\author{
Hanifeh Mirtavoos Mahyari ${ }^{1}$; Adnan Khosravi ${ }^{2, *}$; Zeinab Mirtavoos Mahyari ${ }^{3}$; Zahra \\ Esfahani Monfared ${ }^{4}$; Negin Khosravi ${ }^{5}$ \\ ${ }^{1}$ Chronic Respiratory Disease Research Center, National Research Institute of Tuberculosis and Lung Disease (NRITLD), Shahid Beheshti University of Medical Sciences, Tehran, IR \\ Iran \\ ${ }_{2}^{2}$ Hematology and Medical Oncology, Chronic Respiratory Disease Research Center, National Research Institute of Tuberculosis and Lung Disease (NRITLD), Shahid Beheshti Uni- \\ Hematology and Medical Oncology, Chronic
versity of Medical Sciences, Tehran, IR Iran \\ versity of Medical Sciences, Tehran, IR Iran \\ ${ }_{4}^{3}$ Tehran Medical Branch, Islamic Azad University, Tehran, IR Iran
${ }_{5}^{4}$ ycobacteriology Research Center, National Research Institute of Tuberculosis and Lung Disease (NRITLD), Shahid Beheshti University of Medical Sciences, Tehran, IR Iran \\ ${ }^{5}$ North Tehran Branch, Azad University of Tehran, Tehran, IR Iran \\ ${ }^{*}$ Corresponding Author: Adnan Khosravi, Hematology and Medical Oncology, Chronic Respiratory Disease Research Center, National Research Institute of Tuberculosis and Lung \\ Disease (NRITLD), Shahid Beheshti University of Medical Sciences, Tehran, IR Iran. Tel: +98-2126109946, E-mail: adkhosravi@yahoo.com
}

Received: November 6, 2013; Revised: February 19, 2014; Accepted: March 30, 2014

\begin{abstract}
Background: Patients with early stage breast cancer with same treatment strategy can have markedly different outcomes. Human epidermal growth factor receptor 2 (HER2/nue) gene amplification or the subsequent overexpression of protein has been proved to be associated with patient's outcome and response to anthracyclins-based regimens.

Objectives: This study assessed prognostic value of HER2/nue marker in patients with early stage breast cancer who received adjuvant chemotherapy with anthracyclins-based regimens.

Materials and Methods: Fifty tissue samples from patients with primary breast cancer of moderate risk receiving sequential adjuvant chemotherapy with anthracyclins-based regimens were assessed to evaluate HER2/nue gene status (quantified by Immunohistochemistry and fluorescence in situ hybridization) retrospectively. Besides, correlation of HER2/neu with patients' characteristics and outcome was studied.

Results: HER2/neu amplification was identified in 19 (38\%) of 50 patients. No significant difference regarding HER2/neu status was seen in clinic pathological characteristics of patients. Although Progression Free Survival (PFS) was shorter in HER2 overexpressed group, but uni/multivariate analysis adjusted for HER2 overexpression, nodal involvement, hormone receptor status, age and tumor size revealed no significant predictive and/or prognostic value for HER2 regarding PFS.

Conclusions: This study on a limited number of patients treated with adjutant anthracyclins-based regimens, revealed that HER2/neu is not a unique strong predictor for outcome, thus according to combination of HER2/neu status and other clinical factors, it is necessary to distinguish patients at high risk of recurrence.
\end{abstract}

Keywords:Breast Neoplasms; Oncogenes; Biological Markers

\section{Background}

Breast cancer is one of the most common cancers among females worldwide and the first malignancy affecting Iranian women (1-4). It is assumed that behavior, prognosis, and treatment response are very different in this non-homogenous disease (5). Despite all efforts in early diagnosis, treatment and biomarker identification, about 30\% of patients with early-stage breast cancer would experience recurrence (6). One reason could be drug resistance leading to treatment failure and finally responsible for breast cancer mortality (7). It is believed that breast cancer in the Middle East (where Iran is located in) may be unusually aggressive with an unfavorable prognosis $(8,9)$. Adjuvant chemotherapy, accepted as the main treatment including anthracyclins-based regimens, has been used widely to prevent relapse (10), prolong progression free survival
(PFS) and overall survival (OS) in patients with earlystage breast cancer (11), but sometimes these drugs have serious toxic effects (12). Amplification of human epidermal growth factor receptor 2 (HER2/neu) oncogene has been identified in 20-30\% of invasive breast cancer tumors $(13,14)$. Prognosis and responsiveness to anthracyclins-based therapy could be affected by HER2/neu receptor protein overexpression and gene amplification $(15,16)$. Some investigators believed that the relation between HER2/neu amplification and responsiveness to anthracyclines might be relevant to topoisomerase II $\alpha$. Anthracyclines are topoisomerase inhibitors, and TOP2A is located closely to the HER2/ neu gene on chromosome (17). Generally, several investigators concluded that HER2/neu abnormalities, (either gene amplification or protein overexpression) are

Copyright (C) 2014, Iranian Red Crescent Medical Journal. This is an open-access article distributed under the terms of the Creative Commons Attribution-NonCommercial 4.0 International License (http://creativecommons.org/licenses/by-nc/4.0/) which permits copy and redistribute the material just in noncommercial usages, provided the original work is properly cited. 
associated with a worse prognosis (18). In addition to systemic treatment development, many investigators have a desire to know and classify tumors with poor prognosis, to administer appropriate therapy, and improve patients' outcome. Research has almost focused on comparing anthracyclins to non-anthracyclins based regimens related to HER2/neu over expression $(19,20)$.

\section{Objectives}

In this study, we evaluated HER2/neu prognostic value and outcome of patients with HER2/neu protein overexpression or gene amplification compared to those without such abnormalities when using anthracyclinsbased regimens. It may be possible to find a way to characterize prognostic value of HER2/neu, which can identify tumors with more aggressive behavior in Iranian patients.

\section{Materials and Methods}

This survey was a retrospective single institute study on 50 patients with early stage breast cancer from August 1997 to January 2011 referred to Iranmehr hospital, Tehran, Iran. Informed written consent was obtained prior to enrolling patients in the study according to Shahid Beheshti University of Medical Sciences ethics and scientific committees and was conducted in compliance with the Helsinki Declaration. All patients underwent modified radical mastectomy (MRM) and were treated with postoperative anthracyclins-based chemotherapy. Two anthracyclins containing regimens were administered; CAF $(\mathrm{N}=28)$ versus TAC $(\mathrm{N}=$ 22) regimens. Administration dosages were: 5-Fu 500 $\mathrm{mg} / \mathrm{m}^{2}$, Doxorubicin $50 \mathrm{mg} / \mathrm{m}^{2}$, Cyclophosphamide $500 \mathrm{mg} / \mathrm{m}^{2}$ in CAF (21) and Docetaxel $75 \mathrm{mg} / \mathrm{m}^{2}$, Doxorubicin $50 \mathrm{mg} / \mathrm{m}^{2}$, Cyclophosphamide $500 \mathrm{mg} / \mathrm{m}^{2}$ for TAC (22), repeated every three weeks. Two hundred files of patients with breast cancer were reviewed and 50 cases were included. Inclusion criteria were MRM (Marketing Resource Management) surgery, primary early stage breast cancer who had one to three nodes involvement or had high risk node negative disease (which was defined as primary tumor greater than $2 \mathrm{~cm}$ in size or greater than $1 \mathrm{~cm}$ for tumors both estrogen [ER] and progesterone receptors [PR] negative). Exclusion criteria were metastatic disease or chemotherapy with other regimens. Neither of patients received adjuvant trastuzumab. Formalin paraffin embedded tissue blocks of breast tumors removed during modified radical mastectomy were obtained from archived files of the Pathology Department at Iranmehr Hospital. For hormone receptors and HER2/neu status determining, immunohistochemical methods (IHC) alone (for ER and PR), or IHC and fluorescent in situ hybridization test (FISH) was used. The avidin-biotin-peroxidase method was used for IHC staining. Antibodies were obtained from DAKO Company (Glostrup, Denmark). As recommended ASCO/CAP (23) consensus panel and ESMO guideline (24), first we assessed HER2/neu gene status by immunohistochemistry (IHC). If IHC was $2+$, tumors block underwent confirmatory FISH test. HER2/neu positivity was defined as samples with more than $10 \%$ cells staining $3+$ by IHC or $2+$ by IHC confirmed by FISH (a ratio of HER-2/neu gene/chromosome $17 \geq 2.0$ ). HER2/neu expression was determined by Hercept Tes$\mathrm{t}^{\mathrm{TM}}$ DAKO test. Breast cancer was classified according to WHO classification of breast tumors. In post-treatment follow-up, patients underwent physical examination at least once every four months for the first three years and every six months thereafter. Annual mammograms, bone scans and chest X-rays were performed if necessary.

\subsection{Statistical Analysis}

To examine differences in ordinal variables (tumor size, lymph node involvement, age, and stage) between the two groups (HER2/neu overexpressed in compare with the other), non-parametric Mann-Whitney test was used. Chi-square or Fisher's exact tests were used to compare nominal variables between the two groups when appropriate. Cox proportional hazard model was used to assess adjusted parameters regarding progression free survival (PFS) in uni/multivariate analysis and their 95\% CIs (confidence intervals). For all statistical tests, $5 \%$ level was used as the cutoff for statistical significance. All analyses were performed using SPSS version 16 . As most patients were alive and much exclusion data we did not perform analysis for overall survival. Mean of Kaplan Meier's survival estimates and curves were obtained and the log-rank test was used to assess the significance of differences of PFS between the two study groups. PFS was calculated from date of registration to date of progression or death (Figures 1 and 2).

\section{Results}

Among 50 patients included in this study, 42 (84\%) invasive ductal carcinomas, 6 (12\%) invasive lobular carcinomas and $3(6 \%)$ other pathologies were diagnosed (Figure 3). Age of patients ranged from 26-64. The mean age was 48.4 years. HER2/neu overexpression was found in $38 \%(\mathrm{~N}=19)$ cases. Slightly more cases received adjuvant chemotherapy with CAF regimen $(\mathrm{N}=28)$ than TAC regimen $(\mathrm{N}=22)$. No patient developed symptomatic cardiac dysfunction or irreversible asymptomatic decreases in left ventricular ejection fraction to $50 \%$ or lower. During analysis of postoperative staging of studied cases, the largest group of patients was found in group with stage IIA (Table 1). Lymph node status was assessed during the study, which $46 \%$ of them were involved $(\mathrm{N}=23$ ). There was no significant difference in any of patients' characteristics between the two groups including 
Mirtavoos Mahyari Het al.

tumor size, lymph node involvement, chemotherapy protocol, age, ER/PR status, post-menopausal status, stage and pathology. Clinic pathological characteristics were shown in Table 1. Number of patients without lymphadenopathy involvement was higher in non-over expressed group, but it was not statistically significant (Table 1). In HER2/neu overexpressed tumors, $57.9 \%$ were ER negative, but in the other group 32.3\% were ER negative. Fifteen patients developed a documented relapse (30\%). Mean of PFS in HER2 overexpressed group and the other group were $31.6 \pm 3.2$ and $80.9 \pm 17.4$ months, respectively (HR of relapse $=$ $0.977[0272-0.351$ ], $\mathrm{P}=0.602$, Figure 4 ). We also evaluated the correlation of relapse and PFS with some parameters (listed in Table 2) (For some Parameters, multivariate analysis was not possible because model coefficients and hazard ratio (HR) were not calculated. these parameters were used simple in multivari- ate analysis). In uni/multivariate analysis, neither of them remained significant for PFS means (Table 2).

\section{Discussion}

In this retrospective study, we found no correlation between HER2/neu amplification and prognosis of early stage breast cancer treated by anthracyclins-based regimens in Iranian women. Most studies performed to evaluate the HER2/neu status were conducted in western countries and compared prognostic value of HER2/neu in anthracyclins-based to non anthracyclins-based regimens. In different studies performed in other countries, HER2/neu amplification was found in $20-30 \%$ of breast malignancies $(13,14)$, but in some countries such as Lebanon the higher percentage was reported (25). HER2/neu overexpression in this study is accordance with data from Egypt (25).
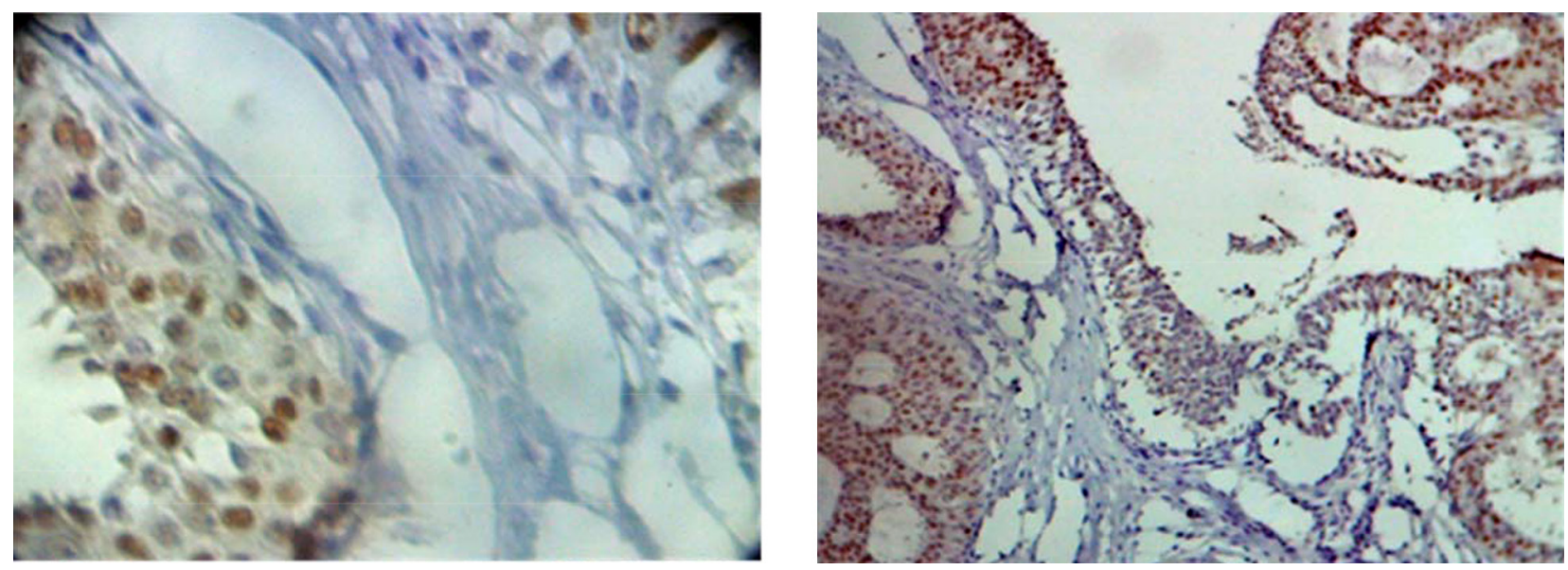

Figure 1. Primary Breast Cancer Estrogen Receptor Immunohistochemical Staining Was Positive
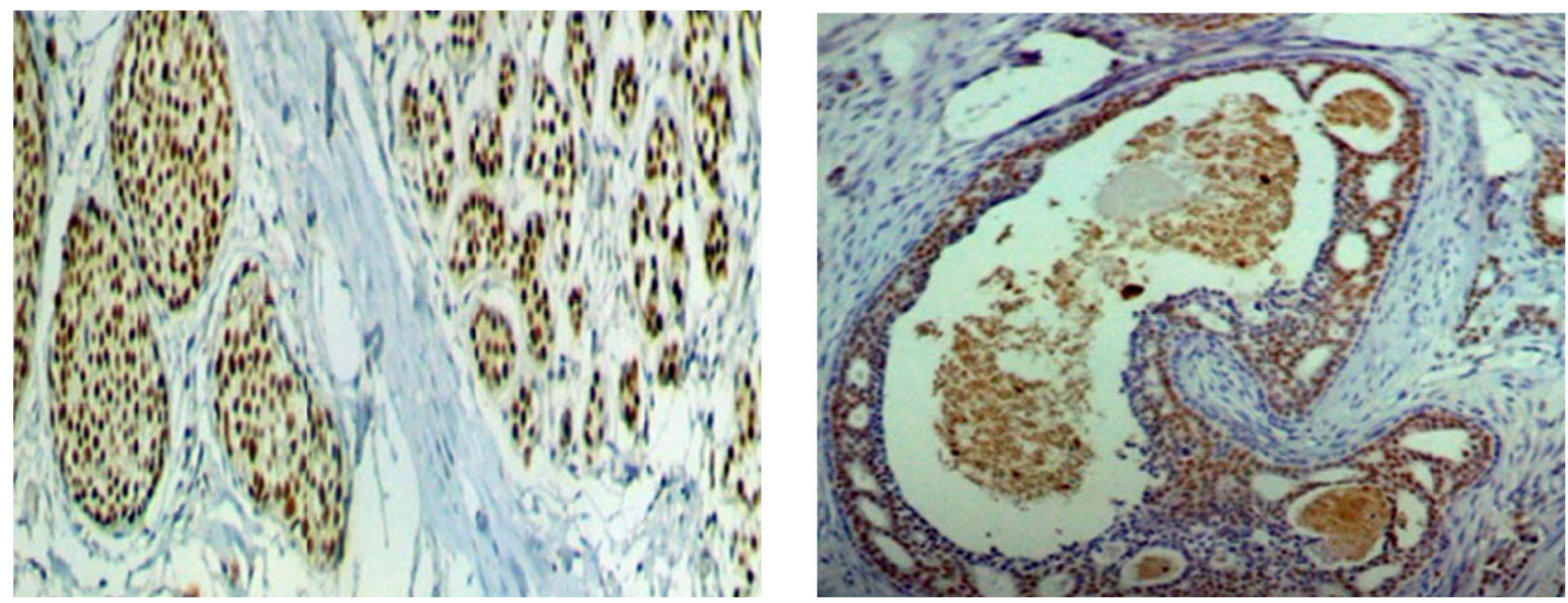

Figure 2. Primary Breast Cancer Progesterone Receptor Immunohistochemical Staining Was Positive 


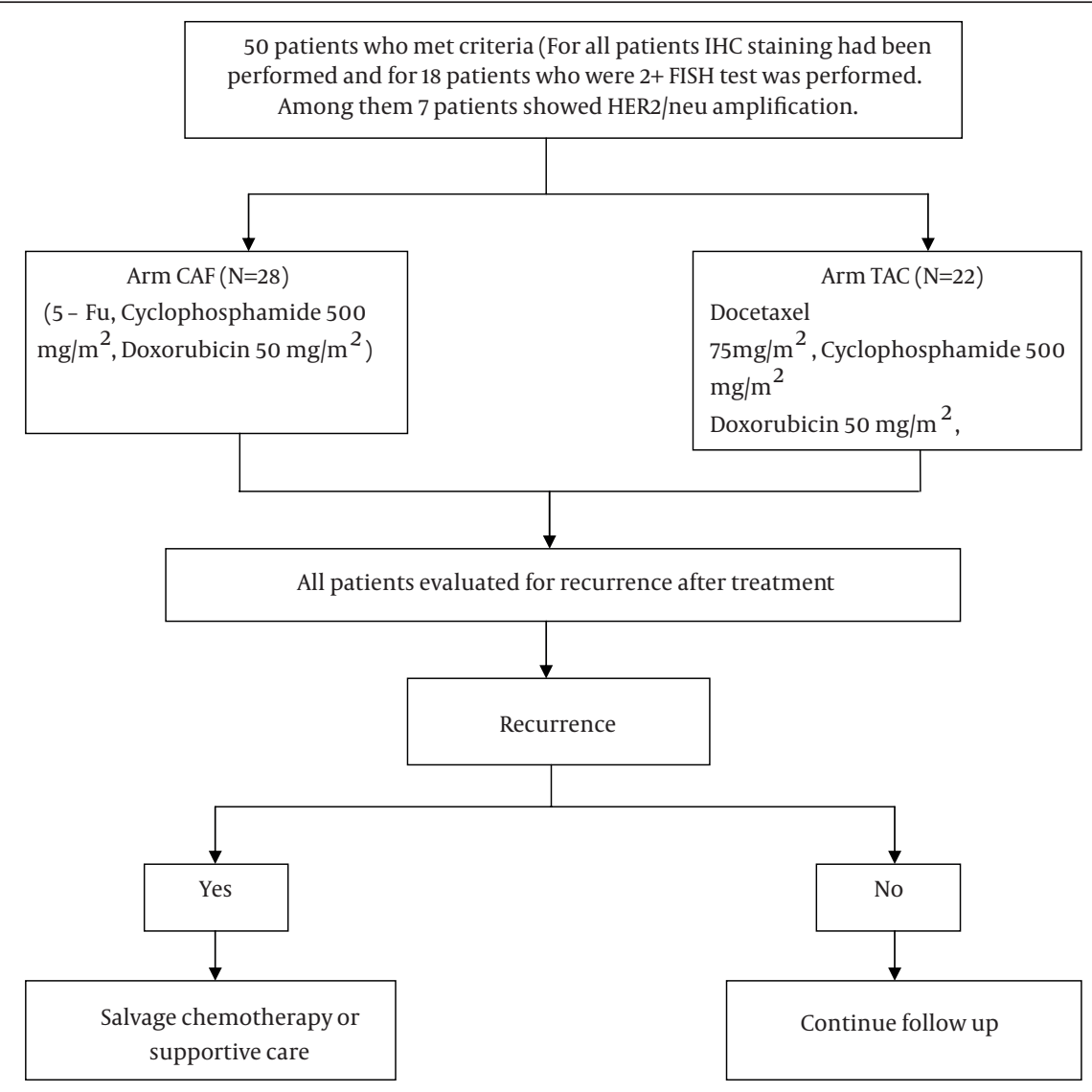

Figure 3. Diagram Details of Materials Used for This Study

Table 1. Clinic pathological Characteristics of Patients ${ }^{\mathrm{a}, \mathrm{b}}$

HER2/neu Amplification gene Group; HER2/neu Not Amplification gene Group; N P Value $\mathrm{N}=19$ $=31$

\begin{tabular}{|lccc}
\hline Age & & & 0.914 \\
9 Years & $1(5.3)$ & $3(9.7)$ \\
\hline $30-39$ Years & $2(10.5)$ & $4(12.9)$ \\
\hline $40-49$ Years & $8(42.1)$ & $10(32.3)$ \\
\hline 50 Years & $8(42.1)$ & $14(45.2)$ & 0.494 \\
\hline Stage & & & $1(3.2)$ \\
\hline IA & $1(5.3)$ & $3(9.7)$ \\
\hline IB & $2(10.5)$ & $16(51.6)$ \\
\hline IIA & $7(36.8)$ & $9(29.0)$ \\
IIB & $6(31.6)$ & $2(6.5)$ \\
\hline IIIA & $3(15.8)$ & \\
\hline ER & & $21(67.7)$ \\
\hline Positive & $9(47.4)$ & $10(32.3)$ \\
\hline Negative & $10(52.6)$ & 0.153 \\
\hline
\end{tabular}


Mirtavoos Mahyari Het al.

\begin{tabular}{|c|c|c|c|}
\hline Positive & $8(42.1)$ & $21(67.7)$ & \\
\hline Negative & $11(57.9)$ & $10(32.3)$ & \\
\hline \multicolumn{2}{|l|}{ Chemotherapy Protocol } & & 0.675 \\
\hline CAF & $11(57.9)$ & $17(54.8 \%)$ & \\
\hline TAC & $8(42.1)$ & $14(45.2 \%)$ & \\
\hline Node + & $8(47.4)$ & $15(48.4 \%)$ & 0.944 \\
\hline \multicolumn{2}{|l|}{ Number of LAP ${ }^{C}$} & & 0.633 \\
\hline 0 & $10(52.6)$ & $16(51.6)$ & \\
\hline 1 & $4(21.1)$ & $4(12.9)$ & \\
\hline 2 & $4(21.1)$ & $6(19.4)$ & \\
\hline 3 & $1(5.3)$ & $5(16.1)$ & \\
\hline \multicolumn{2}{|l|}{ Tumor size $^{d}$} & & 0.765 \\
\hline $1 \mathrm{Cm}$ & $2(10.5)$ & $2(6.5)$ & \\
\hline $1-1.99 \mathrm{Cm}$ & $9(47.4)$ & $18(58.1)$ & \\
\hline $2-4.99 \mathrm{Cm}$ & $6(31.6)$ & $9(29.0)$ & \\
\hline $5 \mathrm{Cm}$ & $2(10.5)$ & $2(6.5)$ & \\
\hline Post-menopausal status & $10(52.6)$ & $14(45.1)$ & 0.833 \\
\hline \multicolumn{2}{|l|}{ Pathology } & & 0.28 \\
\hline Invasive ductal carcinoma & $19(100)$ & $23(74.3)$ & \\
\hline Invasive lobular carcinoma & 0 & $6(19.3)$ & \\
\hline Others & 0 & $2(6.4)$ & \\
\hline \multicolumn{4}{|c|}{ 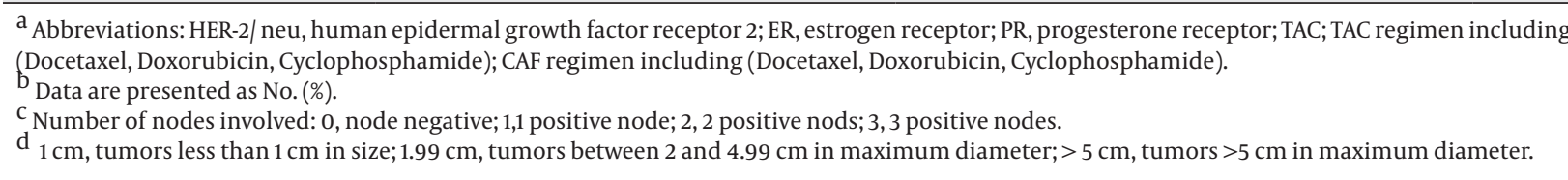 } \\
\hline
\end{tabular}

Figure 4. Kaplan-Meier Survival Curve From the Onset of Recurrence for the Effect of Her2/Neu Gene Amplification on Progression Free Survival

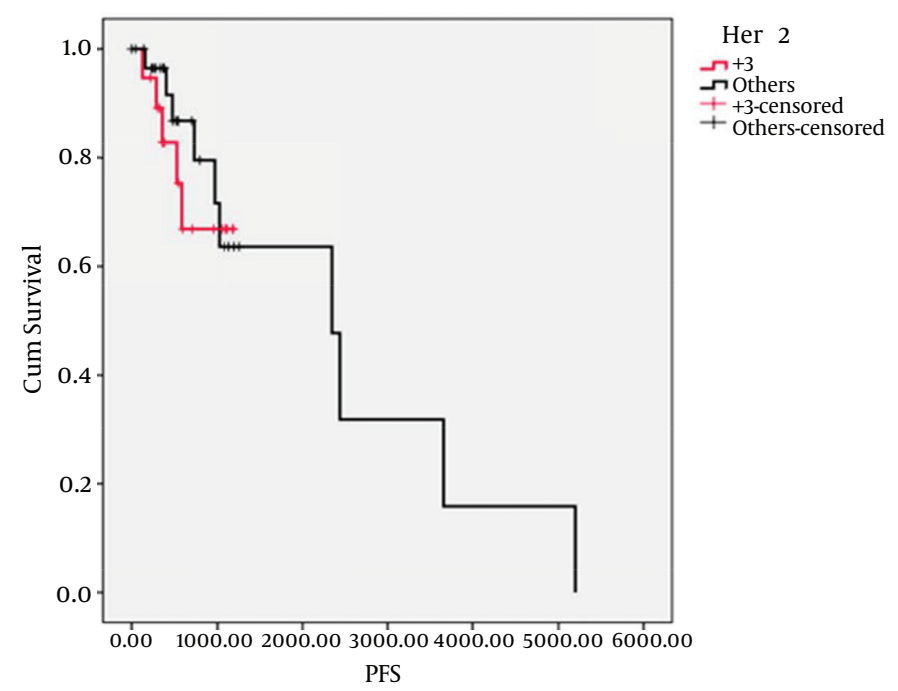

Non-significant shortened PFS was observed in HER2/neu overexpressed group $(\mathrm{P}=0.602)$. 
Mirtavoos Mahyari Het al.

\begin{tabular}{|c|c|c|c|c|}
\hline & \multicolumn{2}{|c|}{ Univariate Analysis } & \multicolumn{2}{|c|}{ Multivariate Analysis } \\
\hline & $\mathrm{HR}(95 \% \mathrm{CI})$ & PValue & $\mathrm{HR}(95 \% \mathrm{CI})$ & PValue \\
\hline HER 2/neu & $1.370(0.417-4.501)$ & 0.604 & $0.977(0.272-3.510)$ & 0.971 \\
\hline Age & & 0.999 & & \\
\hline$\leq 29 \mid \geq 50$ & - & - & - & - \\
\hline $30-39 \mid \geq 50$ & $0.960(0.158-5.849)$ & & & \\
\hline $40-49 \mid \geq 50$ & $1.071(0.316-3.636)$ & & & \\
\hline Age & $1.021(0.956-1.090)$ & 0.530 & $1.017(0.940-1.099)$ & 0.680 \\
\hline $\mathrm{ER}+$ & $0.411(0.137-1.233)$ & 0.113 & $0.350(0.096-1.281)$ & 0.113 \\
\hline Node $+^{\mathrm{c}}$ & $1.191(0.385-3.685)$ & 0.762 & $1.399(0.377-5.192)$ & 0.616 \\
\hline Tumor Size & & 0.193 & & \\
\hline \multicolumn{5}{|l|}{$\leq 1 \mathrm{Cm} / \geq 5 \mathrm{Cm}$} \\
\hline $1-1.99 \mathrm{Cm} / \geq 5 \mathrm{Cm}$ & $0.223(0.044-1.141)$ & & & \\
\hline $2-4.99 \mathrm{Cm} / \geq 5 \mathrm{Cm}$ & $0.116(0.015-0.874)$ & & & \\
\hline Tumor Size $^{d}$ & $1.473(0.900-2.413)$ & 0.124 & $1.567(0.921-2.664)$ & 0.098 \\
\hline Chemotherapy protocol CAF/TAC & $0.788(0.226-2.749)$ & 0.708 & $0.525(0.116-2.368)$ & 0.402 \\
\hline
\end{tabular}

a Abbreviations: HER-2, human epidermal growth factor receptor 2; ER, estrogen receptor; PR, progesterone receptor.

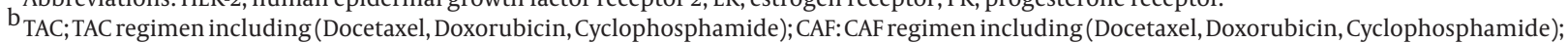
ER +: ER positive.

${ }^{\mathrm{C}}$ Lymph nodes involvement (For some parameters, multivariate analysis was not possible because model coefficients and hazard ratio (HR) were not calculated. These parameters were used simple in multivariate analysis).

$\mathrm{d}_{1 \mathrm{~cm}}$, tumors less than $1 \mathrm{~cm}$ in size; $1.99 \mathrm{~cm}$, tumors between 2 and $4.99 \mathrm{~cm}$ in maximum diameter; $>5 \mathrm{~cm}$, tumors $>5 \mathrm{~cm}$ in maximum diameter.

In patients aged 50 years, HER2/neu overexpression was found in $39.2 \%$, whereas in women over 50 it was detected in $36.2 \%$. It was shown in other studies that in a group of younger female breast cancer, worse prognosis was associated with overexpression of HER2/neu, which leads to more aggressive tumor behavior (26). Tumor size, hormone receptor status, HER2 overexpression and expression of p53 have been identified previously as indicators in breast cancer $(27,28)$ and correlation of HER2 gene overexpression with other parameters indicative of disease relapse has been shown $(29,30)$. We designed this study in a HER2-unselected population to examine whether above findings could be repeated. Although ER/PR negative status and tumor size $>5 \mathrm{~cm}$ were more prevalent in HER2/neu amplified group, it was not statistically significant. Neither of tumor characteristics remained significant regarding HER2/neu status in both uni and multivariate analyses. This finding was verified by similar results from Huang et al. (30) and BadowskaKozakiewicz et al. (31). PFS in HER2/neu non-over expressed group was very much, but not statistically significant in our study. Some researchers showed that in early breast cancer HER2/neu overexpression is a major and potentially risk of relapse $(3,33-38)$, while others did not $(31,39)$. Although our results are not robust but it seems consistent with the report of Tubbs et al. (11). Nevertheless, high levels of HER2/neu amplification had a correlation with worse disease free survival, but some studies suggested that anthracycline-based therapy improved the outcome of patients with HER2 amplification profile (24). Thus in our population of patients who all received anthracyclins-based regimens, the overall outcome would be worse in absence of treatment but with anthracyclins-based therapy more benefit was obtained. Paradoxical results between our results and others could be explained by several factors such as technical and methodological differences or different dosages of drugs and small sample size. However, evaluation of predictive and/or prognostic relevance of this biomarker supposed to perform prospective randomized clinical trial. Finally, this article suggested that distinguishing patients at high risk of recurrence must be based on combination of HER2 status and other clinical factors. Our data does not provide additional information how to improve management of patients with early stages breast cancer and high risk of recurrence. If it is supposed that they would receive standard anthracyclinsbased regimens, higher percentage of HER2/neu overex- 
pression in Iranian breast tumors calls for attention to detect HER2/neu in all breast samples.

\section{Acknowledgements}

The authors wish to thank all patients who participated in the study and helped us. Besides, it is necessary to thank Dr. Naser Etamdi Moghadam.

\section{Authors' Contributions}

Conception and design: Dr. Hanifeh Mirtavoos Mahyari and Dr. Adnan Khosravi. Collection and assembly of data: Dr. Zeinab Mirtavoos Mahyari and Negin Khosravi. Manuscript writing: Dr. Hanifeh Mirtavoos Mahyari and Dr. Zahra Esfahani Monfared.

\section{References}

1. Sadjadi A, Nouraie M, Mohagheghi MA, Mousavi-Jarrahi A, Malekezadeh R, Parkin DM. Cancer occurrence in Iran in 2002, an international perspective. Asian Pac J Cancer Prev. 2005;6(3):35963.

2. Siegel R, Ward E, Brawley O, Jemal A. Cancer statistics, 2011: the impact of eliminating socioeconomic and racial disparities on premature cancer deaths. CA Cancer J Clin. 2011;61(4):212-36.

3. Assi HA, Khoury KE, Dbouk H, Khalil LE, Mouhieddine TH, El Saghir NS. Epidemiology and prognosis of breast cancer in young women. JThorac Dis. 2013;5 Suppl 1:S2-8.

4. Zaha DC, Lazar E, Lazureanu C. Clinicopathologic features and five years survival analysis in molecular subtypes of breast cancer. Rom J Morphol Embryol. 2010;51(1):85-9.

5. Del Mastro L, Bruzzi P, Nicolo G, Cavazzini G, Contu A, D'Amico $M$, et al. HER2 expression and efficacy of dose-dense anthracycline-containing adjuvant chemotherapy in breast cancer patients. Br J Cancer. 2005;93(1):7-14.

6. Gonzalez-Angulo AM, Morales-Vasquez F, Hortobagyi GN. Overview of resistance to systemic therapy in patients with breast cancer. Adv Exp Med Biol. 2007;608:1-22.

7. Kakarala M, Wicha MS. Implications of the cancer stem-cell hypothesis for breast cancer prevention and therapy. J Clin Oncol. 2008;26(17):2813-20.

8. Al Tamimi DM, Shawarby MA, Ahmed A, Hassan AK, AlOdaini AA. Protein expression profile and prevalence pattern of the molecular classes of breast cancer--a Saudi population based study. BMC Cancer. 2010;10:223.

9. Runnak MA, Hazha MA, Hemin HA, Wasan AA, Rekawt RM, Michael HD. A population-based study of Kurdish breast cancer in northern Iraq: hormone receptor and HER2 status. A comparison with Arabic women and United States SEER data. BMC Womens Health. 2012;12:16.

10. Hortobagyi GN. Treatment of breast cancer. $N$ Engl J Med. 1998;339(14):974-84.

11. Tubbs R, Barlow WE, Budd GT, Swain E, Porter P, Gown A, et al Outcome of patients with early-stage breast cancer treated with doxorubicin-based adjuvant chemotherapy as a function of HER2 and TOP2A status. J Clin Oncol. 2009;27(24):3881-6.

12. Early Breast Cancer Trialists' Collaborative G. Effects of chemotherapy and hormonal therapy for early breast cancer on recurrence and 15-year survival: an overview of the randomised trials. Lancet. 2005;365(9472):1687-717.

13. Ross JS, Slodkowska EA, Symmans WF, Pusztai L, Ravdin PM, Hortobagyi GN. The HER-2 receptor and breast cancer: ten years of targeted anti-HER-2 therapy and personalized medicine. Oncologist. 2009;14(4):320-68.

14. Fountzilas G, Valavanis C, Kotoula V, Eleftheraki AG, Kalogeras KT, Tzaida O, et al. HER2 and TOP2A in high-risk early breast cancer patients treated with adjuvant epirubicin-based dose-dense sequential chemotherapy. J Transl Med. 2012;10:10.
15. Paik S, Bryant J, Tan-Chiu E, Yothers G, Park C, Wickerham DL, et al. HER2 and choice of adjuvant chemotherapy for invasive breast cancer: National Surgical Adjuvant Breast and Bowel Project Protocol B-15. J Natl Cancer Inst. 2000;92(24):1991-8.

16. Brase JC, Schmidt M, Fischbach T, Sultmann H, Bojar H, Koelbl H, et al. ERBB2 and TOP2A in breast cancer: a comprehensive analysis of gene amplification, RNA levels, and protein expression and their influence on prognosis and prediction. Clin Cancer Res. 2010;16(8):2391-401.

17. Pritchard KI, Shepherd LE, O'Malley FP, Andrulis IL, Tu D, Bramwell VH, et al. HER2 and responsiveness of breast cancer to adjuvant chemotherapy. N Engl J Med. 2006;354(20):2103-11.

18. Petrelli F, Barni S. Role of HER2-neu as a prognostic factor for survival and relapse in pT1a-bNoMo breast cancer: a systematic review of the literature with a pooled-analysis. Med Oncol. 2012;29(4):2586-93.

19. Spears M, Kenicer J, Munro AF, Bartlett JM. Type I receptor tyrosine kinases as predictive or prognostic markers in early breast cancer. Biomark Med. 2008;2(4):397-407.

20. Pritchard KI, Messersmith H, Elavathil L, Trudeau M, O'Malley F, Dhesy-Thind B. HER-2 and topoisomerase II as predictors of response to chemotherapy. J Clin Oncol. 2008;26(5):736-44.

21. Martin M, Villar A, Sole-Calvo A, Gonzalez R, Massuti B, Lizon J, et al. Doxorubicin in combination with fluorouracil and cyclophosphamide (i.v. FAC regimen, day 1, 21) versus methotrexate in combination with fluorouracil and cyclophosphamide (i.v. CMF regimen, day 1,21 ) as adjuvant chemotherapy for operable breast cancer: a study by the GEICAM group. Ann Oncol. 2003;14(6):833-42.

22. Martin M, Segui MA, Anton A, Ruiz A, Ramos M, Adrover E, et al. Adjuvant docetaxel for high-risk, node-negative breast cancer. N Engl J Med. 2010;363(23):2200-10.

23. Wolff AC, Hammond ME, Schwartz JN, Hagerty KL, Allred DC, Cote RJ, et al. American Society of Clinical Oncology/College of American Pathologists guideline recommendations for human epidermal growth factor receptor 2 testing in breast cancer. Arch Pathol Lab Med. 2007;131(1):18-43.

24. Aebi S, Davidson T, Gruber G, Castiglione M, Esmo Guidelines Working Group . Primary breast cancer: ESMO Clinical Practice Guidelines for diagnosis, treatment and follow-up. Ann Oncol. 2010;21 Suppl 5:v9-14.

25. el AT, Khalifa A, Kamel AS. Immunohistochemical expression of p53 and c-erbB2 proteins in breast cancer in Egypt. Anticancer Res. 2000;20(3B):2145-50

26. Nikolenyi A, Sukosd F, Kaizer L, Csorgo E, Voros A, Uhercsak G, et al. Tumor topoisomerase II alpha status and response to anthracycline-based neoadjuvant chemotherapy in breast cancer. Oncology. 2011;80(3-4):269-77.

27. Park HS, Kim S, Kim K, Yoo H, Chae BJ, Bae JS, et al. Pattern of distant recurrence according to the molecular subtypes in Korean women with breast cancer. World J Surg Oncol. 2012;10:4.

28. Hartmann LC, Ingle JN, Wold LE, Farr GH, Jr., Grill JP, Su JQ, et al. Prognostic value of c-erbB2 overexpression in axillary lymph node positive breast cancer. Results from a randomized adjuvant treatment protocol. Cancer. 1994;74(11):2956-63.

29. Tetu B, Brisson J. Prognostic significance of HER-2/neu oncoprotein expression in node-positive breast cancer. The influence of the pattern of immunostaining and adjuvant therapy. Cancer. 1994;73(9):2359-65.

30. Huang HJ, Neven P, Drijkoningen M, Paridaens R, Wildiers $H$, Van Limbergen E, et al. Association between tumour characteristics and HER-2/neu by immunohistochemistry in 1362 women with primary operable breast cancer. J Clin Pathol. 2005;58(6):611-6.

31. Badowska-Kozakiewicz AM, Sobol M, Patera J, Kozlowski W. Immunohistochemical evaluation of human epidermal growth factor receptor 2 and estrogen and progesterone receptors in invasive breast cancer in women. Arch Med Sci. 2013;9(3):466-71.

32. Tiwari RK, Borgen PI, Wong GY, Cordon-Cardo C, Osborne MP. HER-2/neu amplification and overexpression in primary human breast cancer is associated with early metastasis. Anticancer Res. 1992;12(2):419-25.

33. Chen L, Romond E, Chokshi S, Saeed H, Hodskins J, Stevens M, et 
al. A prognostic model of early breast cancer relapse after standard adjuvant therapy and comparison with metastatic disease on initial presentation. Breast Cancer Res Treat.2012;136(2):565-72.

34. Slamon DJ, Clark GM, Wong SG, Levin WJ, Ullrich A, McGuire WL. Human breast cancer: correlation of relapse and survival with amplification of the HER-2/neu oncogene. Science. 1987;235(4785):177-82.

35. Dubsky PC, Gnant MF, Taucher S, Roka S, Kandioler D, PichlerGebhard B, et al. Young age as an independent adverse prognostic factor in premenopausal patients with breast cancer. Clin Breast Cancer. 2002;3(1):65-72.

36. Piccart M, Lohrisch C, Di Leo A, Larsimont D. The predictive value of HER2 in breast cancer. Oncology. 2001;61 Suppl 2:73-82.

37. Mlineritsch B, Ressler S, Greil R. The role of biomarkers in the choice of therapy in breast cancer. Memo Mag Eur Med Oncol. 2012;5(2):101-4.

38. Goncalves A, Vassilakopoulou M, Spano JP. [Small HER2-positive breast cancer: which prognosis and which adjuvant treatment?]. Bull Cancer. 2013;100(9):847-56.

39. Di Leo A, Isola J, Piette F, Ejlertsen B. A meta-analysis of phase III trials evaluating the predictive value of HER2 and topoisomerase II alpha in early breast cancer patients treated with CMF or anthracycline-based adjuvant therapy. Cancer Res . 2009;69(2):99s. 